\title{
Overcurrent Relay Setting Model for Effective Substation Relay Coordination
}

\author{
Uma U.Uma, I.K.Onwuka \\ Akanu Ibiam Federal Polytechnic Unwana \\ Micheal Okpara University Umudike
}

\begin{abstract}
Relay protection setting of substation plays a very vital role for power system safe operation. But in the recent years power demand has increase substantially while the expansion of the system has been severely limited due to abnormalities of Isolation of faulty areas by the protection system as a result of lack of effective coordination of the relay operation. The main objective of this paper is to design a computer based model using different characteristics equation of overcurrent relay (Standard Inverse, Very Inverse and Extremely Inverse) for determination of different relay parameters. This paper also present the relay setting and coordination of a $132 / 33 \mathrm{kV}$ typical substation with expected short circuit of $2044.5 \mathrm{~A}$ and $800 \mathrm{~A}$ at the respective busbars. Graphic user interphase (GUI) a subprogram of MATLAB is used. The results of the actual operating time and time multipiler setting (TMS) of different relay are determined.
\end{abstract}

Keywords: - Relay Coordination, NEPLAN, MATLAB

\section{INTRODUCTION}

Deregulation of electricity has brought new suppliers into the electicity market resulting in the power system operating close to its peak limit and requires good protection system against any fault[1]. Protection system for power system has been developed to minimize damage and make sure supply is safe, continous and economical. This is a achieved using relay. A relay is device that makes measuremt or receivers signal that causes it to operate and effect the operation of other equipments. It responds to abnormal conditions in faulty section of the system with minimum interruption of supply[2]. Relay co-ordination plays an important role with protection scheme. It is an integral part of the overall system protection and is absolutely necessary to Isolate only the faulty circuit, prevent tripping of healthy circuit[3]. The main purpose of this paper is to design a computer model to calculate the time setting multiplier (TSM) and pick up current Iset of each relay so that the overall operating time of the primary relays is minimized properly. For optimal coordination, these parameters should fulfill all constraints under the operating time and lead to optimal coordination of overcurrent relay. Each part of the system is protected by a main and back up relay and no interference could occur in relay operation [4]. For a good protection scheme, a reliable back up should exist in case the main protective system fails. This backup protection should act as a backup either in the same station or in the neighbouring lines with a time delay according to the selective requirement [5].

\section{Classification of Relays}

Relays are classified based on different properties.

Timing characteristics

Instantaneous relay,Definite time lag relay,Inverse time lag relay,Inverse definite minimum time (IDMT) lag relay.

Application of relays

Over voltage, over current and over power relays, Directional or reverse power relay,Differential relay,Distance relay.

Connection of Sensing Element

Primary relay,Secondary relay.

Actuating quantity

Current, voltage, power, reactance, impedance and frequency relay

\section{Overcurrent Protection}

Overcurrent protection is that protection in which the relay picks up when the magnitude of current exceeds the pick up level. If a short circuit occurs the circuit impedance is reduced to a low value and therefore a fault is accompanied by large current [4]. Overcurrent protection is the protection from overloads. Overloading of a power system equipment means that the equipment is taking more current than its rated current and is also 
associated with temperature rise of the equipment whose permissible limit is based on insulation class and material problems. The basic element in overcurent protection is the overcurrent relays.

\section{Overcurrent Relay}

Overcurrent relays are those relays that respond to current only. The relay will operate if the current passing through the operating coil are higher than the threshold current. The threshold current are the set current below which the relays must not operate and above which they should operate[6]. Basically overcurrent relay is a type of protective relay which operates when the load current exceeds a preset value. They generally have current setting multipliers ranging from 50 to $200 \%$ in steps of $25 \%$ which is refered to as plug setting [PS] for each relay is determined by the fault current [7]. Depending upon the time of operations overcurent relays may be classified as

\section{Instantaneous Overcurrent Relay}

These are the relays whose time of operation depend entirely on the factors inherent in the manufacturing process without any time delay deliberately introduced. The operating time of such relays can be of the order of milliseconds. It will operate at the same time irrespective of the magnitude of the current, as long as the current is higher than the pick up value. It is used for restricted earthfault and circulation current protection.

\section{Inverse Time Overcurrent Relay}

This is a relay whose operating time is approximately inversely proportional to the magnitude of the actuating quantity.

$\mathrm{T}=$ Operating time, Aand $\mathrm{B}=$ scalar constant

$$
T=\frac{A}{I^{\infty}-B} \ldots \ldots \ldots .1
$$

The more pronounced the effect is the more

inverse the characteristic will be. The operating time of all overcurrent relays tends to become asymptotic to a definite minimum value with the increase in the value of actuating quantity. This is inherent in electromagnetic relays due to saturation of magnetic circuit. This effect is takecare by varying the point of saturation which leads to different kinds of IDMTL.

\section{Standard Inverse Definite Time Relay}

These are relay whose operating time is approximately inversely proportional to fault current near pick up value and becomes substantially constant slightly above the pick up value of the relay

$\operatorname{SIR}(t)=\frac{0.14}{P_{S m}{ }^{0.02}-1} \ldots \ldots \ldots \ldots .2$

SIR =standard Inverse Relay

Psm=plug setting multiplier

$$
\begin{aligned}
& P S M=\frac{I_{\text {set }}}{P m} \ldots \ldots \ldots \ldots \ldots \ldots \ldots \ldots \ldots
\end{aligned}
$$

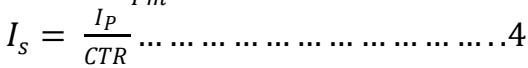

$$
\begin{aligned}
& I_{S}=\text { Secondary Current } \\
& I_{p}=\text { Primary Current }
\end{aligned}
$$

\section{Extremely inverse Relay}

This relay are use for the protection of transformer, cables and feeders because it is possible to achieve accurate discrimination with fuses and auto reclosures in their case.

$\operatorname{EIR}(t)=\frac{80}{P_{s m^{2}-1} \ldots \ldots \ldots \ldots \ldots \ldots \ldots \ldots . . .}$

\section{Very Inverse Relay}

Relays with this characteristics saturation of core occurs at a still later stage as shown in figure 1. The time current characteristic is inverse over a greater range and after saturation tends to definite time. This type of relay are employed in feeders and long sub transmission lines. 


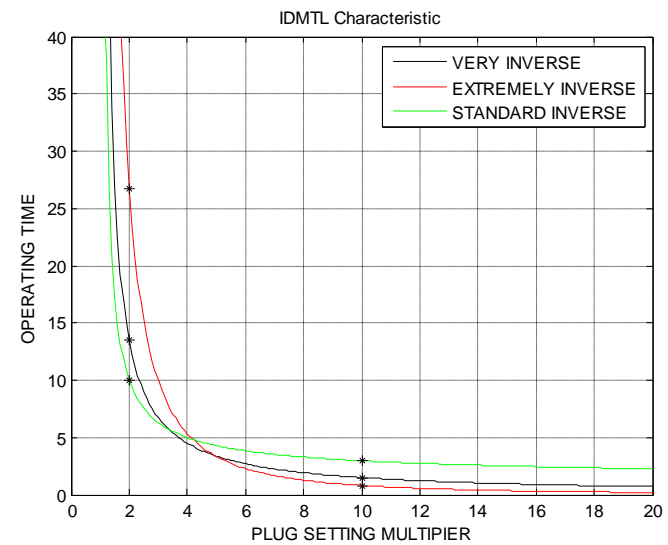

figure 1. Comparison of IDMTL Relay characteristic

\section{CURRENT SETTINGS AND TIME SETTINGS}

The current settings of IDMTL relays are generally expressed in terms of plug setting. (Ps) for the older relays or Iset for the newes relays. In order relays, the plug setting are in discrete steps starting $50 \%$ to $200 \%$ of the nominal rating of the overcurrent. In modem relay, the selection of current setting are generally through toggle switches representing fractions of the nominal current which can be switched in or out. Time settings are determined by the setting of the time multiplier TM for a particular fault current. In the older relays, the Tm is either continuously adjustable and of range $0-1$ or in discrete steps starting from 0.1-1. For the newer relays, the setting of TM is also through togyle switche, with a range $0.025-1$.

\section{RELAY COORDINATION}

Coordination of relay is an integral part of the overall system protection and is absolutely necessary to isolate only the faulty areas and prevent tripping of healthy circuit. A corrent relay co ordination can be achieved by any or all the following methods. Current graded system, Time graded system or discriminative fault protection,Combination of time and current grading

\section{COORDINATION PROCEDURE}

The correct application and setting of relay requires a knowledge of the fault current at each part of the power system network. The following data are required for finding out the setting of the relay.

1. A single line diagram of the power system.

2.The impedance of the transformers, feeders, in ohm or in PU.

3.The maximum peak load current in feeder and full load current of transformer.

4. Maximum and minimum short circuit current that are expected to flow.

5.Type and rating of the protective devices and transformer.

The time interval of operation between two adjecent relays depends upon a number of factors;

$>$ The fault current interrupting time of the circuit breaker.

$>$ The overshoot time of the relay

$>$ Variation in measuring devices errors.

$>$ Factors of safety.

\subsection{Algorithm For Relay Setting}

Step 1. Read in the field data: $\mathrm{H}$ igh and Low voltages of the line, short circuit current, primary and secondary current of HV. CT, primary and secondary current of LV. CT, time graded margin and time setting multiplier [TMS].

Step 2 Calculate the relay current $\left[\boldsymbol{I}_{\boldsymbol{R} 1}\right]$ using equation[6]

$I_{R 1}=\frac{\text { Fault current }}{\text { CT ratio }}$ 6

Step 3. Calculate the pick up value of relay 1. $\left(P U_{1}\right)$ using equation(7)

$\mathrm{CS}=$ Current Setting

$$
P U_{1}=\frac{C S * R C S}{100} \ldots \ldots \ldots \ldots . . .7
$$

RCS =rated current of secondary CT

Step 4. Calculate the plug setting multiplier (Psm 1$)$ using equation(8)

$$
\boldsymbol{P s m}_{1}=\frac{\boldsymbol{I}_{R 1}}{\boldsymbol{P U}_{1}} \ldots \ldots \ldots \ldots \ldots \ldots . .8
$$


Step 5. Determine relay type $(\mathbf{t})$ and calculate the time of operation using the following equations(9),(10) and (11)

$$
\begin{aligned}
S I R & =\frac{0.14}{P s m^{0.02}-1} \ldots \ldots \ldots \ldots \ldots . . . . . . . . . .9
\end{aligned}
$$

$$
\begin{aligned}
& S I R=\text { standard } \text { inverse relay }
\end{aligned}
$$

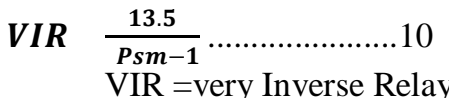

$$
\begin{aligned}
& E I R=\frac{80}{P s m^{2}-1} \ldots \ldots \ldots 11
\end{aligned}
$$

Step 6. Calculate the actual operation time $\left(\boldsymbol{T}_{\mathbf{1}}\right)$ of relay 1 using equation (12)

$$
\boldsymbol{T}_{\mathbf{1}}=\boldsymbol{t} * \boldsymbol{T M S} \text {...............12 }
$$

Step 7. Calculate fault current $\left(\boldsymbol{I}_{\boldsymbol{F} R 2}\right)$ in relay 2 using equation(13)

$$
I_{F R 2}=\frac{\text { Fault current } * \boldsymbol{L V}}{\boldsymbol{H} \boldsymbol{V}} \ldots \ldots . . .13
$$

Step 8. Calculate relay current $\left(\boldsymbol{I}_{\boldsymbol{R} 2}\right)$ in relay 2 using equation(14)

$$
I_{R 2}=\frac{I_{F R 2}}{\text { Relay } 2 \text { CT ratio }}
$$

Step 9. Calculate pick up current of relay 2. $\left(\boldsymbol{P} \boldsymbol{U}_{2}\right)$ using equation(15)

$$
\boldsymbol{P} \boldsymbol{U}_{2}=\frac{\boldsymbol{C S} * \boldsymbol{R S C}}{100} \ldots \ldots \ldots 15
$$

Step 10. Calculata plug setting multiplier of relay 2. (Psm $\left.\boldsymbol{P m}_{2}\right)$ using equation(16)

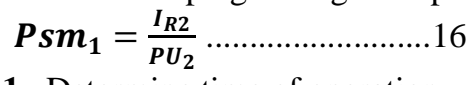

Step 11. Determine time of operation using Step 5

Step12. Calculate the actual operating time of relay $2\left(\boldsymbol{T}_{2}\right)$ using equation(17)

$$
\boldsymbol{T}_{2}=\boldsymbol{t} * \boldsymbol{T M S}+\boldsymbol{T}_{\mathbf{1}} \quad \ldots \ldots .17
$$

Step 13. Relay setting data.

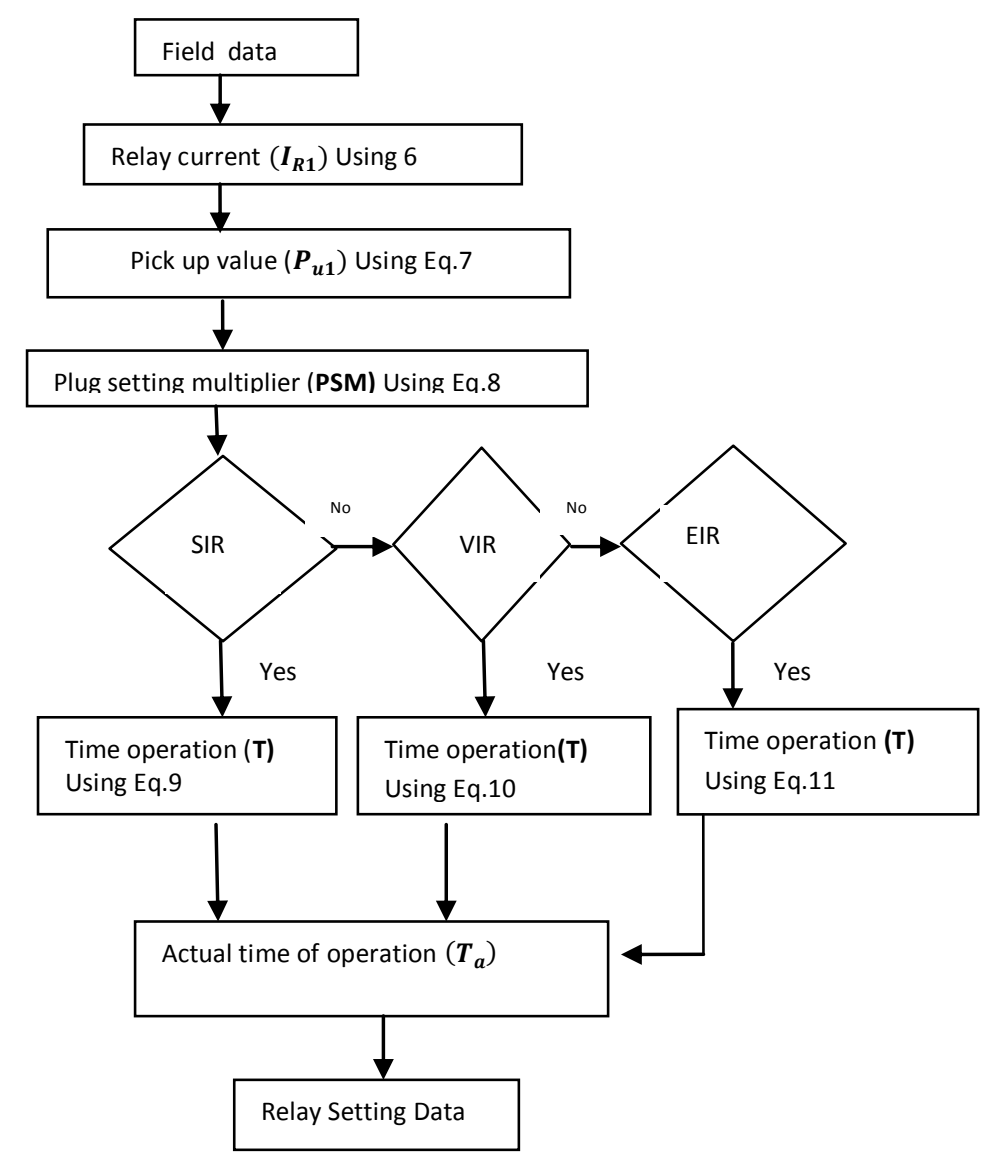

figure 2. Flow chart of overcurrent relay setting. 


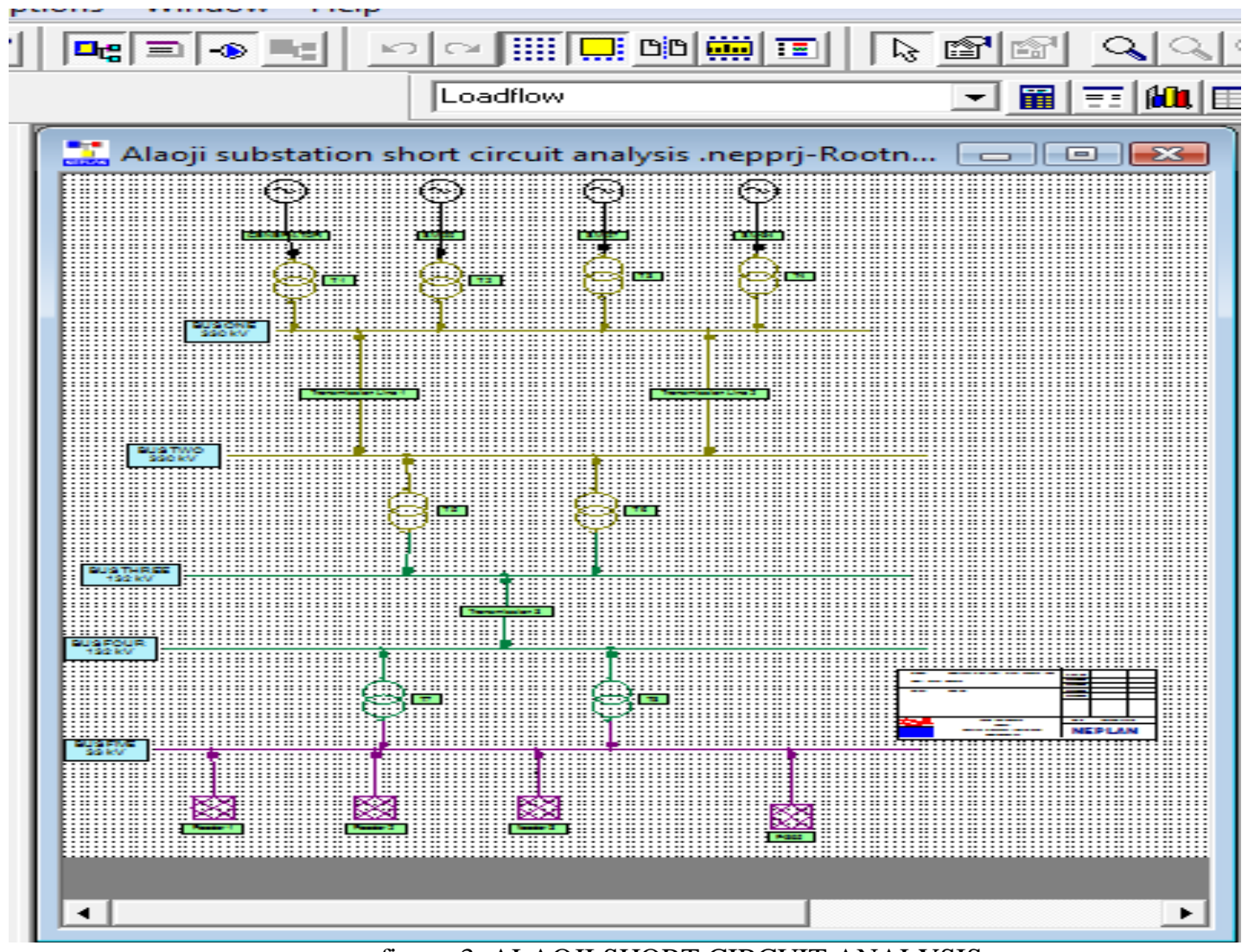

figure 3 ALAOJI SHORT CIRCUIT ANALYSIS

The fault current on $132 \mathrm{kV}$ and $33 \mathrm{kV}$ of Alaoji Substation where calculated using neplan software.the result obtained are as below.

\begin{tabular}{|l|l|}
\hline BUS VOLTAGE $[\mathrm{kV}]$ & FAULT CURRENT[A] \\
\hline 132 & 799.76 \\
\hline 33 & 2455.5 \\
\hline
\end{tabular}

The figures 4,5,\& 6 below, shows different result of the simulation for the determination of different relay settings with all the parameters on the left hand side coming in as the input and the that on the right the output and the graph shows the relationship between the different chracteristics of the relay. [Standard Inverse, Very Inverse and Extremely Inverse relay].

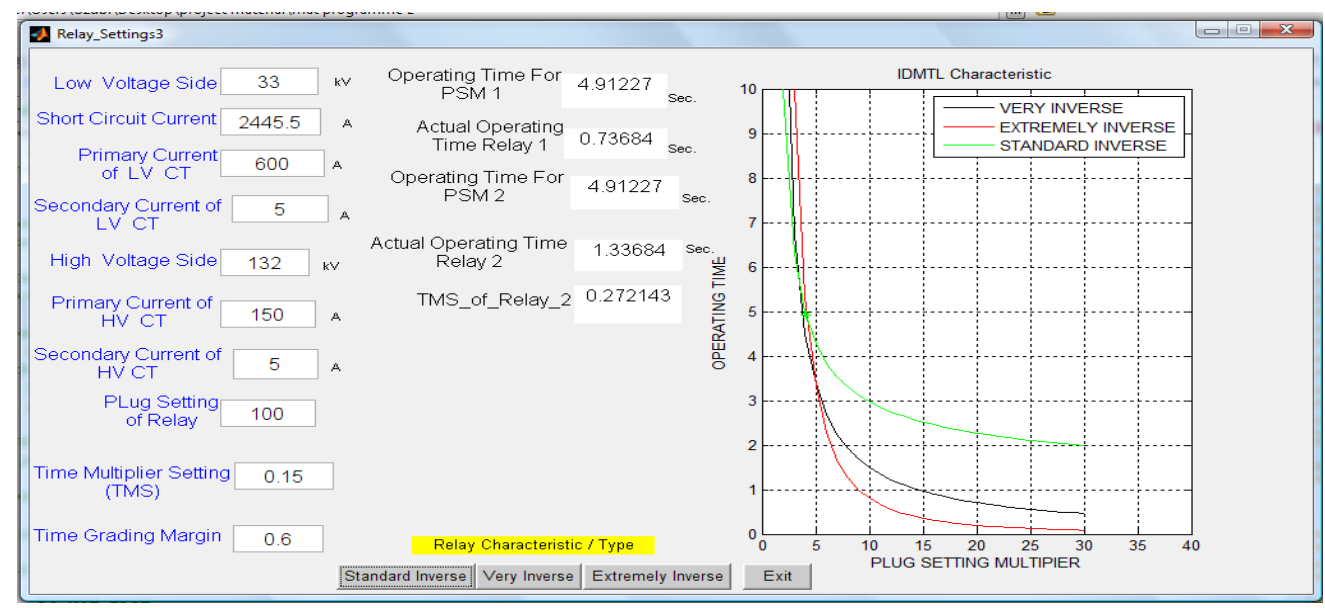

figure 4 Simulation of Very Inverse 


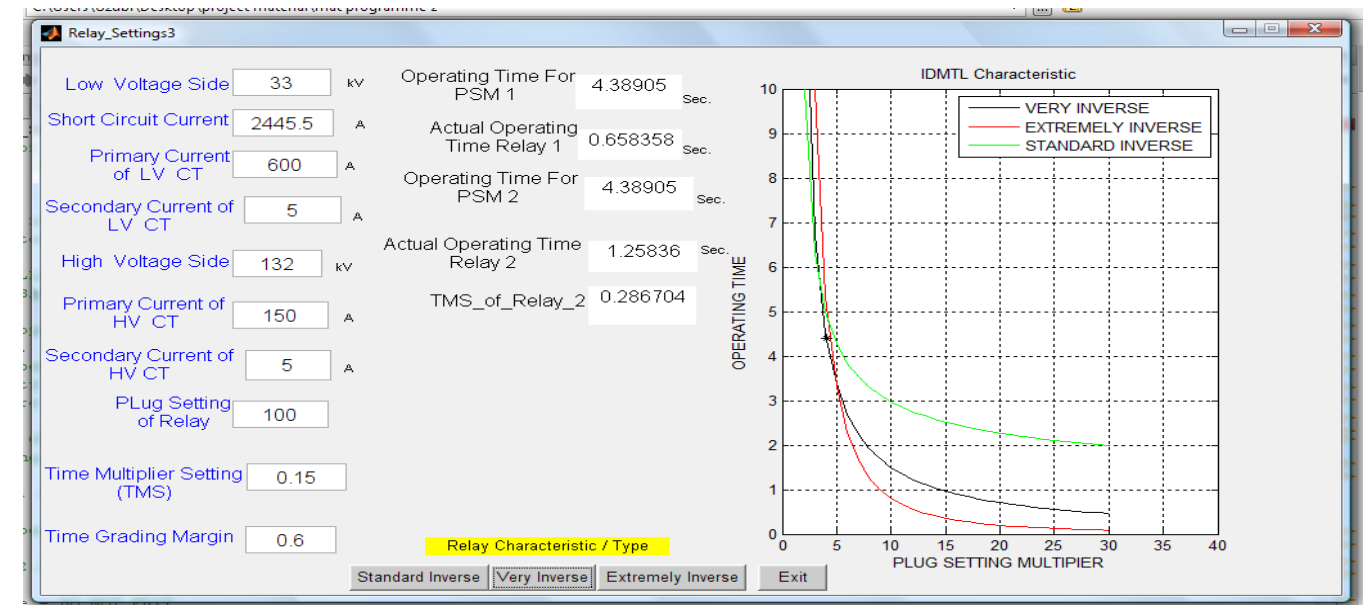

figure 5 Simulation of Extremely Inverse

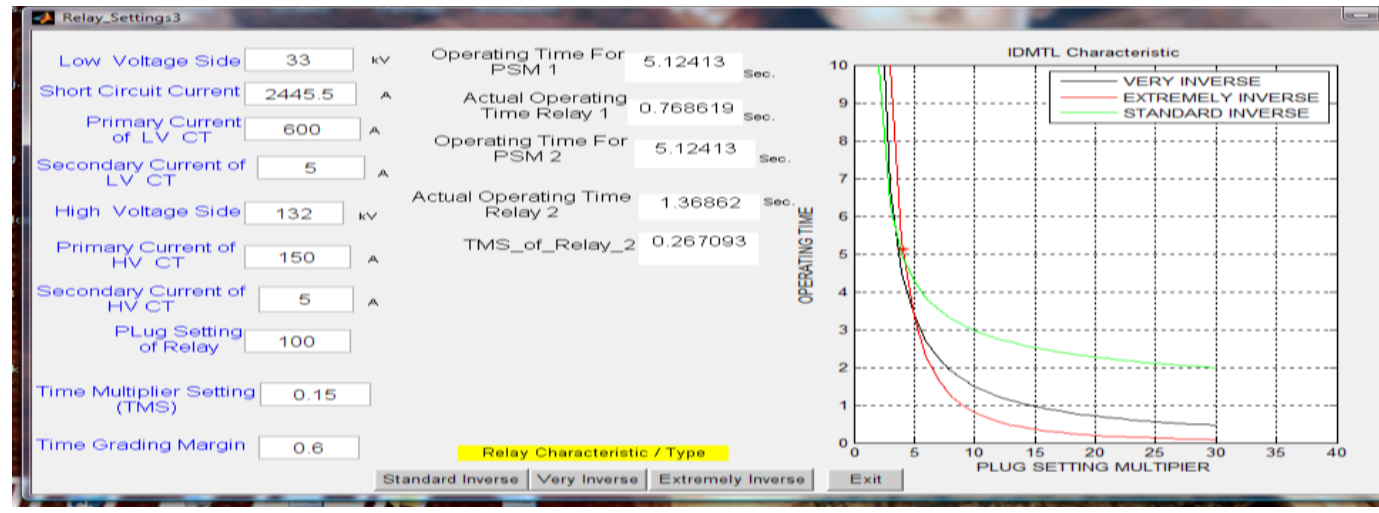

figure 6 Simulation of standard inverse

From the simulation of standard Inverse relay, the actual operating time of relay $1=0.768619 \mathrm{sec}$, and relay $2=1.36862 \mathrm{sec}$ with TMS of 0.267093 . Very Inverse relay, the actual operating time of relay $1=0.73684 \mathrm{sec}$. and relay $2=1.33684 \mathrm{sec}$ with TMS of 0.272143 . Extremely Inverse, the actual operating time of relay $1=0.658358 \mathrm{sec}$. and relay $2=1.25836 \mathrm{sec}$ with TMS of 0.286704 .

\section{CONCLUSION}

It will be concluded that the protection of a $132 / \mathbf{3 3 k V}$ substaion with two bus system and its relay settings have been presented with emphasis only on overcurrent relay. From the above, it will be observed that the time of operation of the extremely Inverse is the smallest followed by Very Inverse and Standard Inverse.The three characteristics of overcurrent relay are considered during relay setting. Extremely Inverse takes care of fault at the far end of the feeder, Very Inverse takes care of the middle and standard Inverse within the substation.

\section{REFERENCES}

[1] Javad Sadeh, " Optimal Coordination of Overcurrent Relay in An Interconnected Power System," $15^{\text {th }}$ PSCC Liege Paper 1, August 2005.

[2] Aniket C.,Ritu B.,and Dhruvi S. “Mathematical and Simulink Analysis of Relay Coordination," IJOER Vol.1.,Issue.4.,2013

[3] Reza mohammadi et.al. " Optimal Relays Coordination Efficient method in Interconnected Power System,'JEE. Vol.61. no2, pp. 75-83, 2010

[4] A.Akbar,M.Birjandi and M. Pourfallah, "Optimal Coordination of Overcurrent and Distance Relays by a New Particle Swarm Optimization Method,’'IJEAT. Vol.1.pp 93-98,December 2011.

[5] NEPA, "Basic Protection Course P1' Training and development program. June 2007

[6] Kri,A.,and Kirpal, S., “A review on protection of transmission line," IJERST, Vol.2,pp.1-5,march 2013.

[7] M.H.Hussan and S.R.A.Rahim, "Optimal Overcurrent Relay Coordination, A review "SSD.Procedia Engineering, 53 pp.332-336,2013 